Supporting Information

\title{
Dual Roles of Polymeric Capping Ligands in the Surface-Protected Etching of Colloidal Silica
}

Ji Feng, ${ }^{\ddagger, a}$ Fan Yang, ${ }^{\ddagger, a}$ Guoxiang Hu, ${ }^{\text {a,b }}$ Tatiana V. Brinzari, ${ }^{c}$ Zuyang Ye, ${ }^{a}$ Jinxing Chen, ${ }^{\text {a }}$ Saide Tang, Shiyou Xu, ${ }^{\mathrm{c}}$ Viktor Dubovoy, ${ }^{\mathrm{c}}$ Long Pan, ${ }^{* c}$ and Yadong Yin*a

a Department of Chemistry, University of California Riverside, California 92521 USA.

b Center for Nanophase Materials Sciences, Oak Ridge National Laboratory, Oak Ridge, Tennessee 37831, USA.

${ }^{\mathrm{c} C}$ Colgate-Palmolive Company, Piscataway, New Jersey 08854, USA

* Correspondence should be addressed to long_pan@colpal.com (Pan) and yadong.yin@ucr.edu (Yin) 


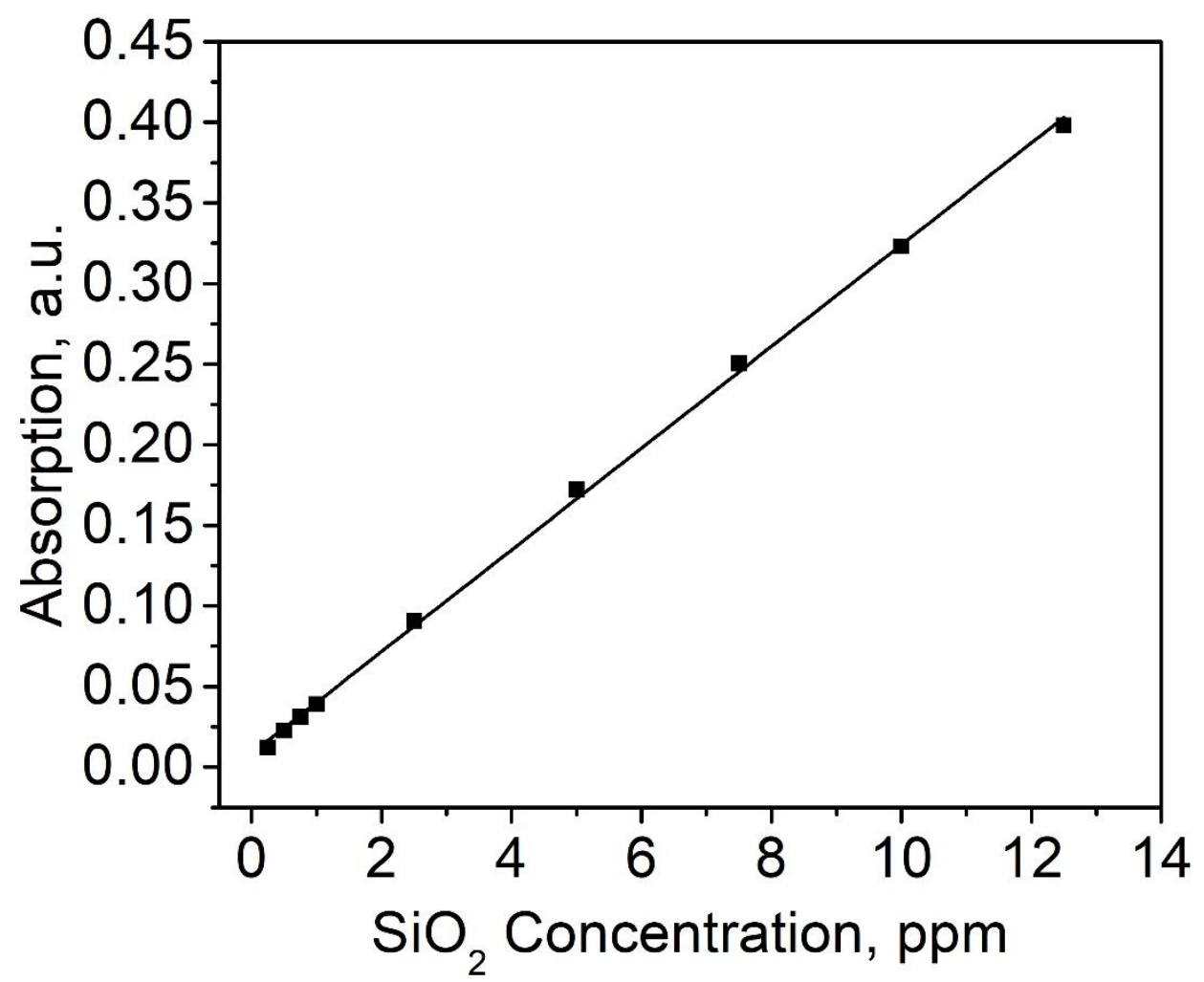

Figure S1. Standard calibration curve of $\mathrm{SiO}_{2}$ concentration. 

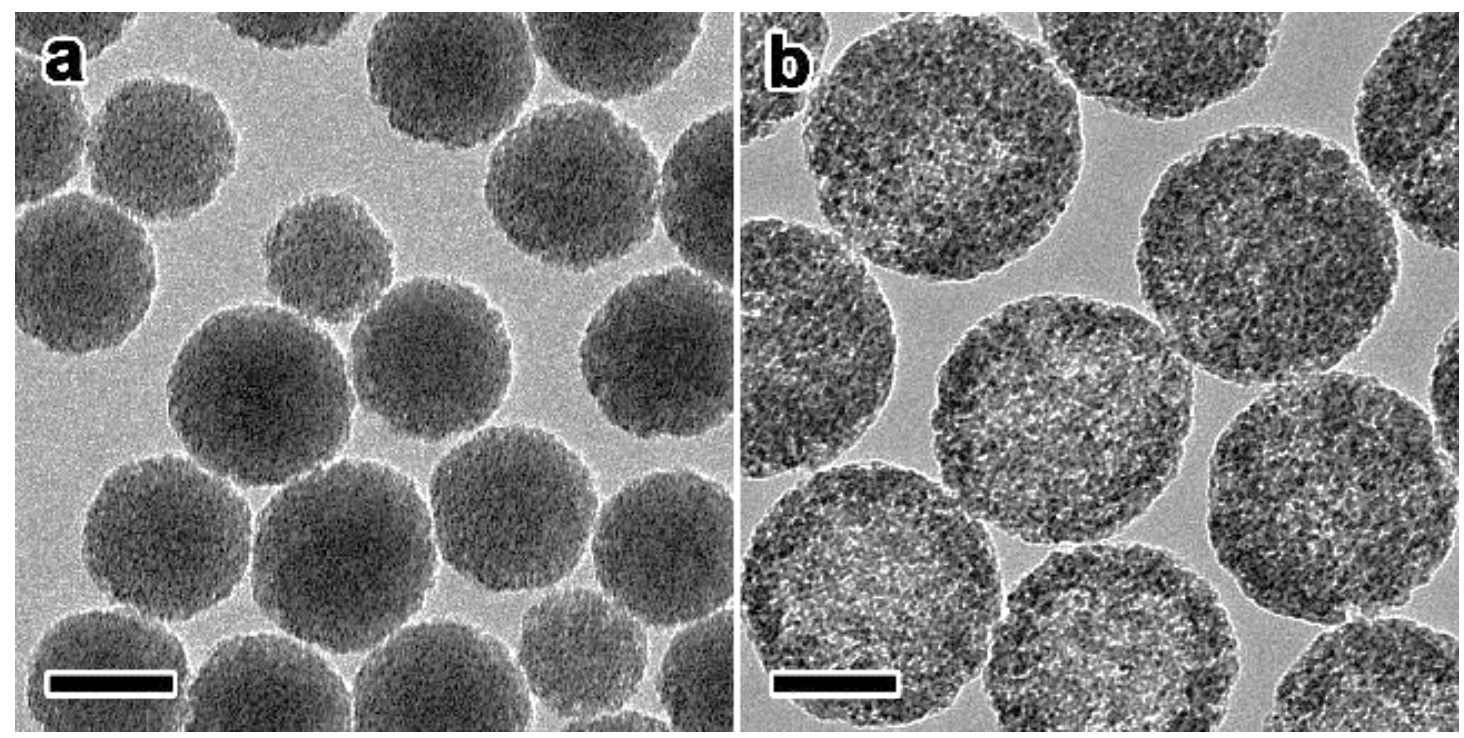

Figure S2. TEM images of (a) as-synthesized Stöber silica nanospheres and (b) PVP-capped silica nanospheres after being etched in $0.33 \mathrm{M} \mathrm{NaOH}$ for $5 \mathrm{hrs}$. The scale bars represent $100 \mathrm{~nm}$. 

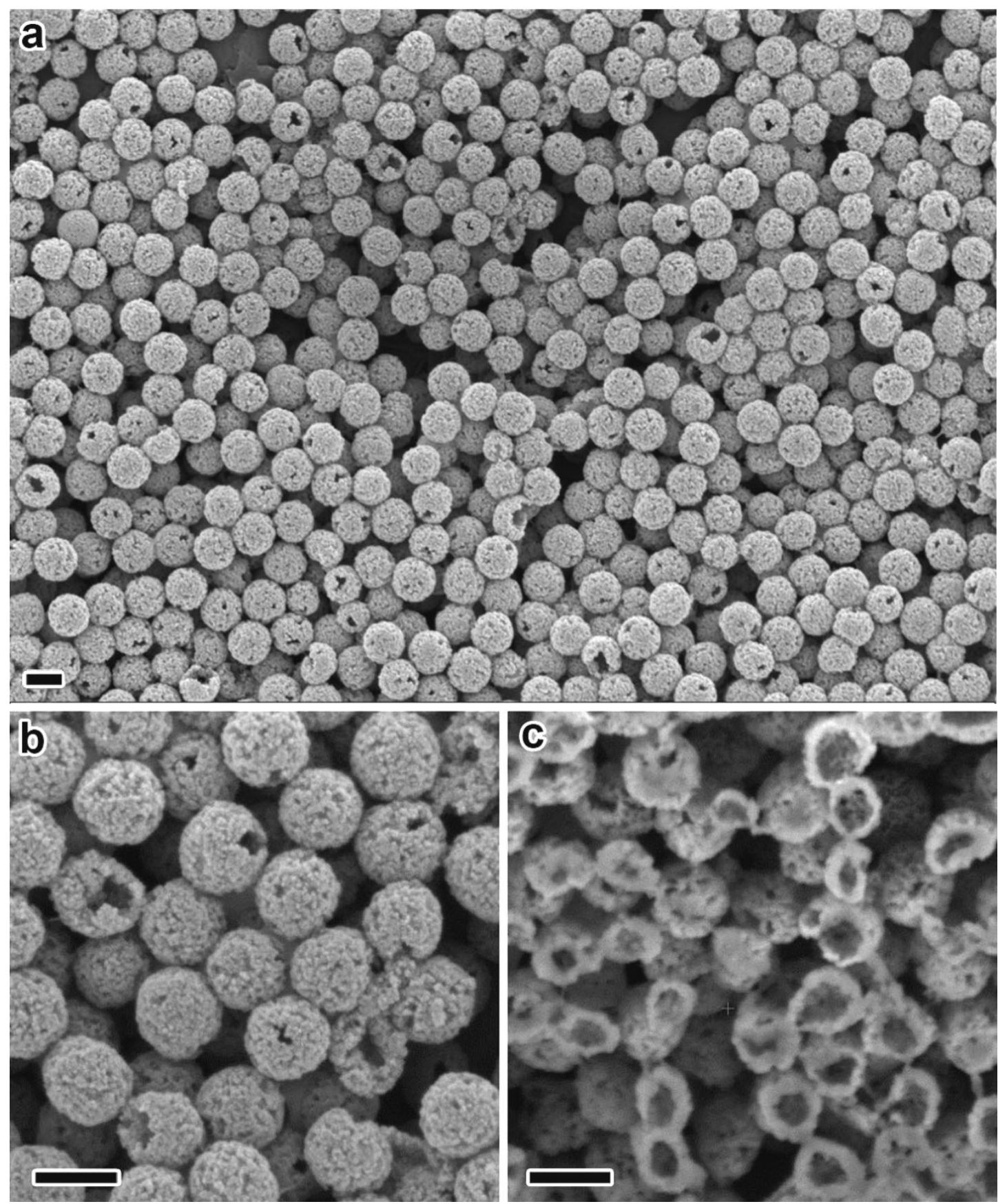

Figure S3. (a, b) SEM images of PVP-capped silica nanospheres being etched in $0.33 \mathrm{M} \mathrm{NaOH}$ for 5 hrs. (c) SEM image of the same sample after ablated by FIB. The scale bars are $200 \mathrm{~nm}$ in (a) and $100 \mathrm{~nm}$ in $(\mathrm{b}, \mathrm{c})$. 


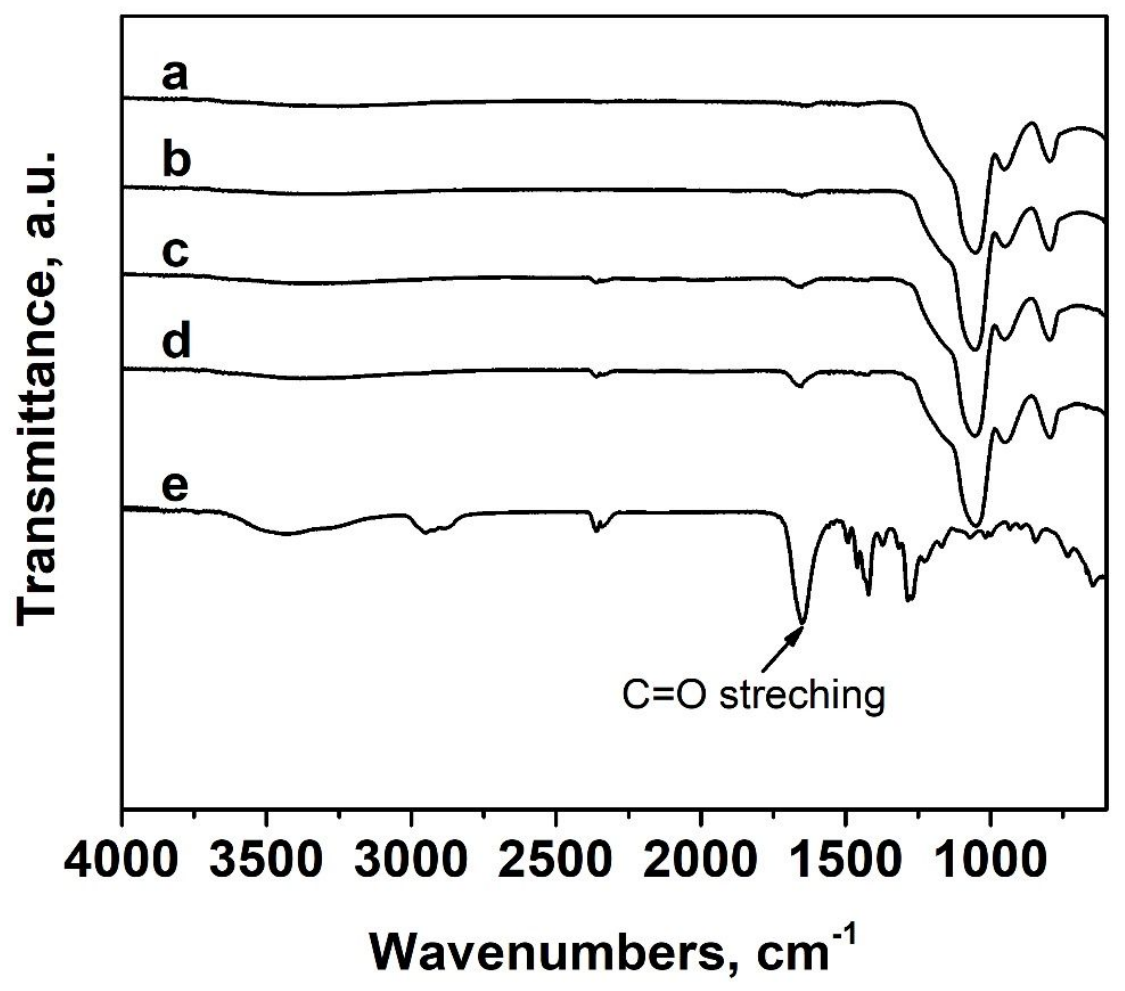

Figure S4. FTIR spectra of (a-d) $\mathrm{SiO}_{2}$ nanospheres being heated at $100{ }^{\circ} \mathrm{C}$ for $3 \mathrm{~h}$ with different molar ratio of PVP/Si and (e) pure PVP. The molar ratio of PVP/Si are (a) 0, (b) 1, (c) 5 and (d) 10. 


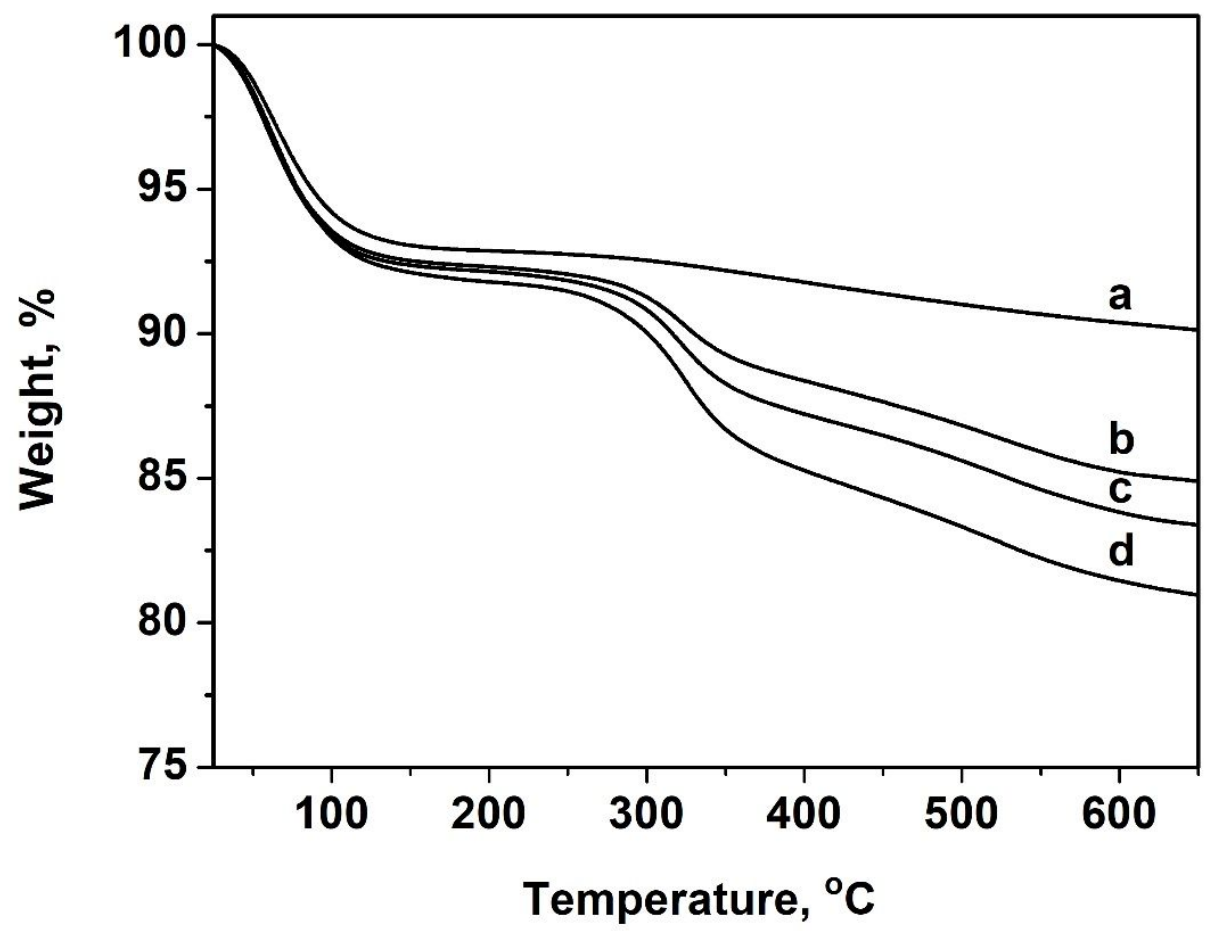

Figure S5. TGA curves of $\mathrm{SiO}_{2}$ nanospheres being heated at $100{ }^{\circ} \mathrm{C}$ for $3 \mathrm{~h}$ with different molar ratio of PVP/Si: (a) 0, (b) 1, (c) 5 and (d) 10. 


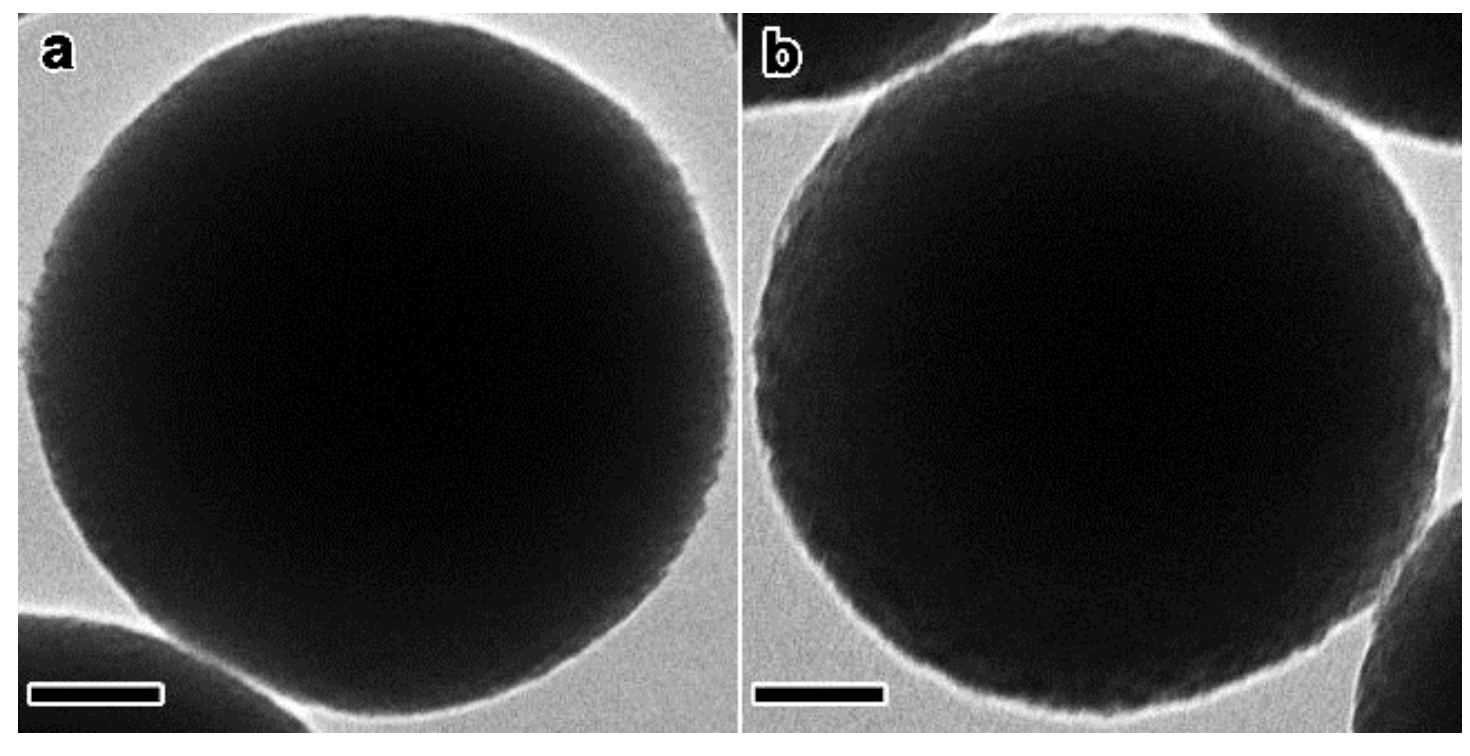

Figure S6. TEM images of silica nanospheres being heated at $100{ }^{\circ} \mathrm{C}$ (a) with PVP and (b) without PVP. The scale bars represent $50 \mathrm{~nm}$. 


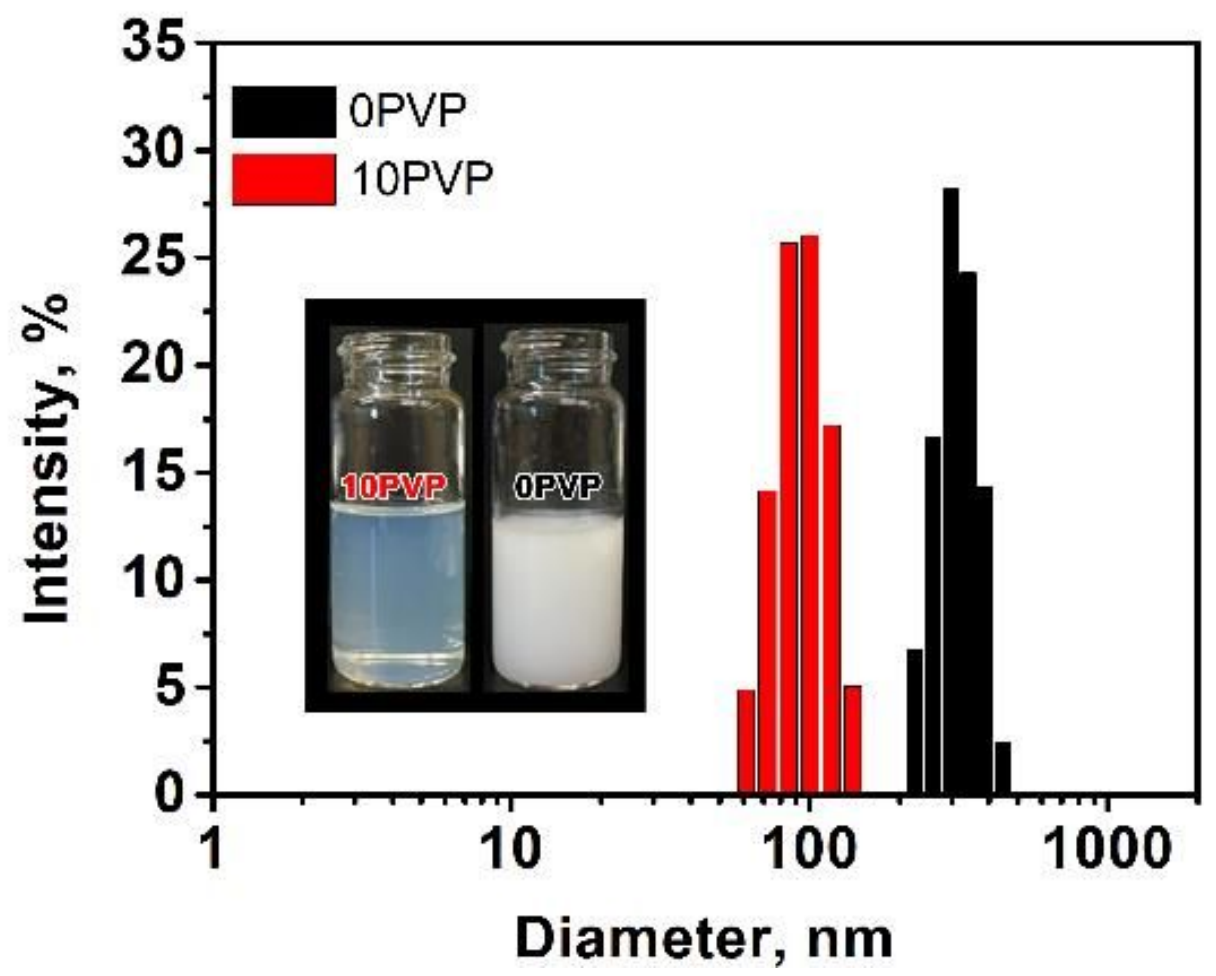

Figure S7. Size distribution of silica nanospheres synthesized with and without PVP. The inset digital image shows the appearance of the nanospheres after synthesis. 